\title{
Balanced Scorecard: ferramenta Auxiliar na definição da Estratégia de TI alinhada ao Negócio
}

\author{
Balanced Scorecard: auxiliary tool in the determination of IT Strategic Aligned to Business
}

Caroliny Almeida Soares, Universidade Católica de Brasília, carolinysoares@gmail.com

José Gonçalo dos Santos, Instituto Federal de Educação, Ciência e Tecnologia de Brasília, jose.santos@ifb.edu.br

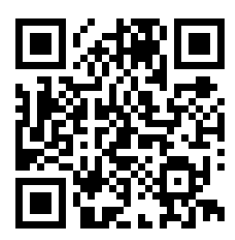

Resumo: Saber aonde se quer chegar é algo importante na definição de estratégias. 0 grande desafio está em sua manutenção e integração com as áreas. Caso isso não ocorra, o insucesso é algo iminente de ocorrer. Portanto, manter a sinergia para a integração e continuidade das ações deve ser o maior objetivo no processo de definição do planejamento estratégico. Dessa forma, este estudo procurou identificar como o Balanced Scorecard (BSC) pode auxiliar a área de TI em seu processo de definição da estratégia e garantir que este esteja alinhado aos objetivos organizacionais. Com base nos resultados apresentados, foi possível verificar que a aplicação do BSC na definição da estratégia da área de Tecnologia da Informação proporciona uma gestão mais efetiva com resultados satisfatórios, e uma avaliação mais clara no desempenho da área de TI em relação à organização e sua contribuição.

Palavras-cheve: Planejamento Estratégico de TI, Objetivos Organizacionais, Balanced Scorecard.

\begin{abstract}
Know where you want to reach is something important in strategies' defining. The big challenge is it maintenance and integration with some areas. If it doesn't happen, the failure is something inevitable to happen. Therefore, keep the synergy for integration and actions' continuity must be the main objective in the definition process of the strategic planning. That way, this study intended to identify how the Balanced Scorecard can help IT in it definition process of the strategy and to ensure that it is aligned to the organizational goals. Based on the presented results, it was possible to verify that the application of BSC in Information Technology Strategy determination provides an effective management with satisfactory results, and a cleaner evaluation of the IT performance to organization and its contribution.
\end{abstract}

Keywords: IT Strategic Planning, Business Goals, Balanced Scorecard.

Aceiro s organizações objetivam, de forma geral, ganhos financeiros, maturidade organizacional, dinamismo nas relações políticas e econômicas, entre outros benefícios. Mas será que o caminho percorrido é suficiente e/ou adequado para o alcance desses objetivos?

Para essa pergunta, é possível uma resposta se a organização souber qual o seu foco, quais as suas metas e qual a sua estratégia para a consecução do seu objetivo. 0 que significa dizer que as áreas de negócio precisam saber se o que elas produzem como resultados agrega valor à organização.

Kaplan e Norton (2000, p. 18) evidenciaram que "[...] empresas focalizadas na estratégia, ao se referirem à maneira como atingiram resultados extraordinários, mencionaram duas palavras: alinhamento e foco".

Mapear aonde se quer chegar e quais os caminhos a percorrer é um passo fundamental para orientar as áreas em suas definições de projetos e ações operacionais. As áreas de negócio precisam interagir e construir objetivos comuns, pois não há empresa sem interdisciplinaridade nos seus processos.

0 grande desafio talvez esteja em manter a sinergia para a integração e continuidade das ações e abordagens necessárias, esbarrando-se, então, em fatores que podem ser o insucesso das metas organizacionais.

A área de TI não está longe do problema. Na ausência de soluções e ferramentas adequadas ao apoio dos processos de negócio, o dinamismo que as organizações buscam fica a desejar.

"O nível mais elementar de contribuição da informática para as empresas é o da melhoria da eficiência na execução de tarefas que podem ser automatizadas, no todo ou em parte" (Graeml, 2003, p. 88). 
Uma área de TI que não considerar os objetivos estratégicos da organização em que se insere como os seus próprios objetivos, será uma área de TI que deseja apenas ser um simples provedor de tecnologia, haja vista que até mesmo os provedores de tecnologia, atualmente, tendem a preocuparse com a estratégia de negócio de seus clientes, condição básica para a venda de serviços sob demanda (Magalhães \& Brito, 2007, p. 34).

E como gerir essa sinergia para haver integração? A resposta pode estar no uso de uma ferramenta gerencial que seja capaz de definir a estratégia organizacional e auxiliar na trajetória dos objetivos. Na gestão estratégica competitiva, o Balanced Scorecard é um sistema que proporciona essa visão. Mas será que a ferramenta Balanced Scorecard é suficiente para promover o alinhamento estratégico da Tecnologia da Informação ao Planejamento Estratégico Organizacional?

De fato as organizações estão passando por muitos desafios na manutenção do planejamento estratégico, pois as áreas possuem dificuldades em obter resultados que estejam alinhados à estratégia organizacional, por falta de ferramenta de gestão que as subsidie.

Portanto, este trabalho tem como pressuposto alcançar as respostas para atendimento dos seguintes objetivos:

- superar os desafios em estabelecer o alinhamento estratégico organizacional e manter sua execução por meio de suas áreas;

- explorar o nível de maturidade bibliográfica sobre a aplicabilidade do BSC no alinhamento estratégico da TI com o negócio;

- investigar os motivos desafiadores que impactam e reduzem as perspectivas do alcance dos resultados organizacionais;

- analisar o nível de sucesso de uma organização em acolher a ferramenta Balanced Scorecard como norteadora e mantenedora do processo estratégico.

\section{REVISÃO DE LITERATURA}

Uma pesquisa, seja de ordem teórica ou prática, é desenvolvida a partir dos conhecimentos disponíveis e da utilização cuidadosa de métodos, técnicas e outros procedimentos científicos, num processo que envolve inúmeras fases, desde a formulação do problema até a apresentação dos resultados.

Este estudo é de natureza qualitativa e caracteriza-se como exploratório-descritivo. Na abordagem qualitativa, o pesquisador busca entender o fenômeno por meio das pessoas, pontos de vistas diversos, coleta de dados, etc. E, para tanto, utilizou-se a pesquisa exploratória buscando proporcionar um conhecimento mais profundo acerca do assunto escolhido. A pesquisa exploratória tem como objetivo proporcionar uma visão geral de um determinado fato, principalmente quando ele é pouco explorado (GIL, 2002).

Como método, utilizou-se o estudo de caso, que busca analisar uma unidade procurando obter um conhecimento mais específico. Com relação à unidade de análise, o estudo foi realizado em uma empresa do segmento de autogestão de saúde, que possui um porte considerável. Esta foi eleita para este estudo pelo fato de ter implantado o Planejamento Estratégico Organizacional em sua área de tecnologia da informação, com a aplicação do Balanced Scorecard (BSC).

Quanto aos procedimentos técnicos de coleta de dados da empresa escolhida, adotou-se a pesquisa bibliográfica com base nos documentos e relatórios disponibilizados pela empresa. Alguns relatórios de gestão de indicadores foram analisados para compor o estudo sob o aspecto dos resultados da área de tecnologia da informação. Para uma melhor coleta e posterior análise dos dados, procedeu-se da seguinte forma: organização das informações, exploração do material, análise e interpretação (GIL, 2002).

É importante que conceitos e processos envolvidos no planejamento e gestão estratégica sejam analisados, para possibilitar a compreensão da abordagem aplicada pela ferramenta de gestão adotada neste trabalho.

\section{Planejamento}

Planejamento objetiva fundamentalmente traduzir uma estratégia para alcançar resultados e orientar a tomada de decisão.

Planejamento é o processo sistemático consciente de tomada de decisões a respeito das metas e atividades a serem cumpridas no futuro por um indivíduo, um grupo, uma unidade de trabalho ou uma organização. Planejamento não é uma resposta casual ou informal a uma crise; é um esforço proposital, dirigido e controlado pelos gerentes e, muitas vezes, baseado no conhecimento e na experiência de todos os funcionários da organização. 0 planejamento proporciona a indivíduos e unidades de trabalho diretrizes claras a serem seguidas nas atividades futuras; ao mesmo tempo, essas diretrizes podem incluir circunstâncias individuais e condições de mudanças (BATEMAN, 2007, p. 118).

0 planejamento tem se tornado cada vez mais importante para as organizações formais, na medida em que as mudanças tornam-se constantes, provocando um reposicionamento que deve ser rápido e com segurança.

A organização, tratando-se de unidades estrategicamente estruturadas, necessita envolver os níveis hierárquicos no 
momento adequado para formulação da estratégia.

Uma estratégia é um padrão de ações e alocação de recurso projetado para atingir as metas da organização. A estratégia implementada pela organização é uma tentativa de combinar as suas habilidades e os seus recursos com as oportunidades encontradas no ambiente externo; ou seja, toda companhia tem suas forças e fraquezas. As ações ou estratégias implementadas pela organização devem visar fortalecer as áreas que satisfazem os desejos e as necessidades dos consumidores e outros aspectos fundamentais do ambiente externo. Além disso, algumas empresas podem implementar estratégias que alteram e influenciam o ambiente externo [...] (BATEMAN, 2007, p. 122).

Para cada nível hierárquico há uma relação de abrangência de atuação processual e de lideranças.

Tabela 1: Hierarquia Organizacional

\begin{tabular}{|c|c|c|c|}
\hline & $\begin{array}{c}\text { Nivel } \\
\text { Gerencial }\end{array}$ & $\begin{array}{c}\text { Nivel de } \\
\text { Detalhe }\end{array}$ & Prazo \\
\hline Estratégico & Alto & Baixo & Longo \\
\hline Tático & Médio & Médio & Médio \\
\hline Operacional & $\begin{array}{c}\text { Linha de } \\
\text { Frente }\end{array}$ & Alto & Curto \\
\hline
\end{tabular}

Fonte: Bateman, 2007

No planejamento do nível mais alto, o estratégico, as decisões para a organização dizem respeito às metas, e as estratégias são previstas para longo prazo. Para Bateman (2007, p. 122),

os planos estratégicos recebem forte orientação externa e cobrem grande parte da companhia. Os altos executivos são responsáveis pela elaboração e execução do plano estratégico, embora normalmente eles não formulem nem implementem pessoalmente todo o plano.

Os gerentes estratégicos geralmente estabelecem metas que refletem tanto a eficiência quanto a eficácia, pois é preciso envolver os demais níveis hierárquicos. Quanto aos níveis - táticos e operacionais - Bateman (2007, p. 123) esclarece que "Depois de identificados os planos e as metas, estes se tornam a base do planejamento elaborado pelos gerentes de níveis médio e operacional. [...] os planos e as metas tornamse mais específicos e envolvem prazos mais curtos à medida que vão passando do nível estratégico para o tático e, por fim, para o nível operacional".
Os procedimentos e processos específicos necessários aos níveis mais baixos da organização são enquadrados no planejamento operacional. Para Chiavenato (2003), o desenvolvimento de um plano estratégico faz parte de um processo de mudança organizacional que não ocorrerá facilmente mesmo que os objetivos estratégicos promovam a segregação dos objetivos até o nível operacional.

A organização deve procurar o alinhamento entre esses níveis hierárquicos e adequar as iniciativas e operaç̧ões à estratégia de negócio. "Para a total eficácia das metas e dos planos estratégico, tático e operacional, é necessário haver um alinhamento - ou seja, eles devem ser coerentes, mutuamente sustentáveis e focados no alcance de um objetivo em um propósito comum" (BATEMAN, 2007, p. 123).

\section{Planejamento Estratégico EMPRESARIAL (PEE)}

No que tange à estratégia empresarial, Kaplan e Norton (2000) ressaltam que muitas organizações, já no fim da década de 1970, operavam por controle centralizado no topo da hierarquia e por meio de grandes departamentos funcionais.

0 planejamento estratégico colaborava para o desenvolvimento de uma atitude de análise de variáveis da organização ao mesmo tempo em que promovia estudos para a racionalização de processos e ganhos de eficiência.

Sendo assim, no decorrer dessa década, o planejamento estratégico passou a ser visto como um componente indispensável a qualquer corporação que almejasse alcançar desempenhos de destaque, o que resultou em uma enorme influência sobre a prática da administração e sobre os processos de formação de estratégia.

Rezende (2002, p. 20) e esclarece que "O Planejamento Estratégico é um processo dinâmico e interativo para determinação de objetivos, políticas e estratégias (atuais e futuras) das funções empresariais e dos procedimentos de uma organização". Bethlem (1998) comenta que na maior parte das empresas é adotada uma metodologia e um modelo para promover o desenvolvimento estratégico.

Segundo Kaplan e Norton (2000), a implementação da estratégia exige que todas as unidades do negócio, de apoio e empregados, estejam alinhados e conectados com o que a empresa objetiva. E com a rapidez das mudanças na tecnologia, na concorrência e nos regulamentos, a formulação e a prática da estratégia devem converter-se em processo contínuo e participativo. As organizações, hoje, necessitam de uma linguagem para a comunicação, tanto da estratégia como dos processos e sistemas que contribuem para a melhoria organizacional.

Mintzberg, Ahlstrand e Lampel (2000), ao refletirem sobre estratégia, fazem referência a dez escolas relacionadas à 
administração estratégica. As escolas contribuem para uma melhor formulação estratégica nas organizações, destacandose aqui a escola do planejamento cujos proponentes desenvolveram, segundo os autores, extensos procedimentos para explicar e, sempre que possível, para quantificar as metas da organização.

Os autores denominam a primeira fase - implementação do planejamento estratégico - de fixação dos objetivos.

Os próximos estágios, ainda segundo os autores, são os de auditoria externa e interna e avaliação das estratégias; por fim é realizada a programação de todo o processo. Os autores concluem que a operacionalização de estratégias dá origem a todo um conjunto de hierarquias em diferentes níveis e com diferentes perspectivas de tempo.

Dentre os diversos temas que compõem o campo de estudos de estratégia empresarial, o planejamento estratégico tem sido um dos que chamam a atenção pelo volume de discussões das quais foi objeto ao longo dos anos.

Apesar da popularidade conquistada nos círculos de alta gestão desde o seu surgimento na década de 60, a partir dos anos 80, o planejamento estratégico começou a ser questionado. Betlhem (1998) afirma que, no Brasil, poucas são as empresas que produzem um plano estratégico e menos ainda as que são capazes de atualizá-lo quando as mudanças ambientais recomendam mudanças.

\section{Planejamento Estratégico da TECNOLOGIA DA INFORMAÇÃO (PETI)}

Com a necessidade de superar as dificuldades de reagir às mudanças, outras áreas passaram, como a de Tecnologia da Informaçã̃o, a se posicionar no processo de definição da estratégia.

O Planejamento Estratégico da Tecnologia da Informação (PETI) é um processo dinâmico e interativo para estruturar estratégica, tática e operacionalmente as informações e conhecimentos organizacionais, a TI (e seus recursos: hardware, software, sistemas de telecomunicação, gestão de dados e informação), os sistemas de informação e do conhecimento, o perfil das pessoas envolvidas e a infraestrutura necessária para o atendimento de todas as decisões, ações e respectivos processos da organização (Rezende, 2002, p. 20).

Segundo Rezende (2002, p. 56) "A TI desempenha um papel muito importante na redefinição e no planejamento dos negócios empresariais nas organizações, exigindo um posicionamento e planejamento mais estratégico, proativo e efetivo".

Segundo 0 autor, 0 alinhamento entre o PETI e o PEE constitui-se da relação vertical, horizontal, transversal, dinâmica e sinergética das funções empresariais que promovem 0 ajuste ou a adequação estratégica das tecnologias disponíveis de toda a organização.

Em seu conceito, a efetividade nos ganhos empresariais possui seu balizamento no relacionamento do Planejamento Estratégico de Tecnologia da Informação alinhado e integrado ao Planejamento Estratégico Empresarial, que pode ser embasado por alguns elementos fundamentais: sistemas de informação e do conhecimento, as pessoas e o contexto organizacional, por meio de suas respectivas variáveis.

\section{Para Graeml (2003),}

com base nos conceitos e nas justificativas do PETI, fica evidenciada a importância de sua existência, que, derivada do PEE, constitui-se numa efetiva ferramenta de gestão para as organizações que se preocupam com sua inteligência empresarial.

Com isso fica evidenciada a necessidade de o PETI ser elaborado metodologicamente nas organizações, sendo amplamente discutido, avaliado e aprovado por todos os envolvidos, para que seus resultados sejam de qualidade indiscutível, e que possam contribuir com as metas organizacionais.

\section{BALANCED SCORECARD (BSC)}

Com a evolução do pensamento estratégico, o planejamento estratégico foi criticado por alguns autores por seu caráter estático, por não cogitar a existência de estratégias emergentes e por não pôr em prática de forma eficaz a execução dessas estratégias.

O Balanced Scorecard (BSC), por sua vez, trata da execução da estratégia em si, da mensuração dos indicadores de desempenho baseado nas estratégias, a fim de se atingirem os objetivos traçados pela empresa.

Rezende (2002) comenta que o BSC e o planejamento estratégico são complementares e que cada um possui foco em determinada etapa do processo estratégico, cabendo ao planejamento estratégico a função de formulação, e ao BSC, 0 desdobramento e a aplicação.

Ainda conforme Rezende (2002), a maioria das empresas que partiram para o uso do Balanced Scorecard já executava o planejamento estratégico. Para o autor, o BSC supriu a carência do planejamento estratégico, a partir do desdobramento das estratégias formuladas em objetivos, indicadores e iniciativas que passam a ser monitoradas continuamente.

No que tange ao surgimento do BSC, até meados do ano de 1975, o sucesso das empresas dependia do poder da produção em escala. A tecnologia era importante, porém era aplicada 
exclusivamente aos ativos físicos da organização, com intuito de buscar a eficiência operacional. Quanto maior era o rendimento, maior era a produção.

Segundo os autores do Balanced Scorecard (Kaplan \& Norton, 1997), o controle organizacional dessa época baseava-se no monitoramento do capital financeiro e da especialização funcional, pois vislumbrava-se o sucesso dos acionistas.

$\mathrm{Na}$ era da informação, século XX, alguns fundamentos industriais tornaram-se obsoletos. As empresas não conseguem mais obter vantagem com a aplicação de seus recursos somente em ativos físicos; passaram, então, a entender que seus clientes possuem necessidades diferentes.

A especialização funcional ainda é importante, entretanto os processos necessitam de integração e agilidade. A cadeia de suprimento deve proporcionar o atendimento das necessidades dos clientes com imediatismo, e ainda em escala global.

Os autores do BSC comentam que organizações ainda estão utilizando de diversas iniciativas para melhorar sua operação e consequentemente sua competitividade. No entanto, consideram que são dissociadas da estratégia e exigem grandes mudanças no sistema de gestão.

Diante dos cenários, Kaplan e Norton (1997) promovem o BSC como um sistema gerencial que fornece a estrutura necessária para traduzir a estratégia em termos operacionais, visando à melhoria dos processos internos, à valorização do cliente e ao aumento de capacidade de aprendizagem e crescimento. Pretenderam acrescentar à medição do desempenho organizacional indicadores que não fossem apenas os financeiros.

Magalhães e Brito (2007) reportam que a metodologia BSC pressupõe a escolha dos indicadores para administrar uma organização, não apenas os financeiros e os econômicos, sendo necessário monitorar também as perspectivas relacionadas ao mercado, aos processos internos e às pessoas.

Os indicadores utilizados pelo BSC não são definidos aleatoriamente, mas determinados a partir do estabelecimento da missão, visão e estratégia, as quais são desdobradas em objetivos, indicadores, metas e iniciativas que atendam aos fatores: atendimento ao cliente, acionistas, negócio, inovação e aprendizado.

Magalhães e Brito (2007) ressaltam que para se chegar aos desdobramentos da estratégia, devem-se contemplar com respostas as seguintes questões:

- Para o sucesso financeiro, como devemos ser vistos pelos nossos acionistas?

- Para alcançarmos nossa visão, como deveríamos ser vistos pelos nossos clientes?

- Para satisfazermos nossos acionistas e clientes, em quais processos de negócio devemos alcançar a excelência?
- Para alcançarmos nossa visão, como sustentar nossa capacidade de mudar e melhorar?

Havendo respostas para essas perguntas, facilmente a organização conseguirá criar uma relação de causa e efeito sobre os resultados apresentados, que são medidos conforme os indicadores relacionados à estratégia organizacional.

Segundo os autores do BSC (Kaplan \& Norton, 1997), devem-se observar as seguintes perspectivas para definição dos indicadores:

- Perspectiva financeira - A elaboração do Balanced Scorecard deve ser um incentivo para que as unidades de negócios vinculem seus objetivos financeiros à estratégia da empresa e sirvam como foco para os outros objetivos e medidas das outras perspectivas, fazendo parte de uma relação de causa e efeito.

- Perspectiva dos clientes - As empresas identificam os segmentos de mercado onde querem competir. Esses segmentos representam as fontes que irão produzir os componentes de receita dos objetivos financeiros da empresa. A perspectiva de clientes permite que as empresas alinhem suas medidas essenciais de resultado relacionadas aos clientes - satisfação, fidelidade, retenção, captação, lucratividade - com segmentos específicos de clientes e mercados e avaliação das propostas de valor dirigidas a esses segmentos.

- Perspectiva dos processos internos da empresa - Os executivos identificam os processos mais críticos para a realização dos objetivos dos clientes e acionistas. As empresas costumam desenvolver os objetivos e medidas para essa perspectiva, após estabelecer as medidas financeiras e do cliente.

- Perspectiva do aprendizado e crescimento - A implantação de uma estratégia começa pela educação daqueles que têm de executá-la. Um programa de comunicação com base ampla compartilha com todos os empregados a estratégia e os objetivos críticos que eles têm que atingir, se quiserem que a estratégia seja bem sucedida. 


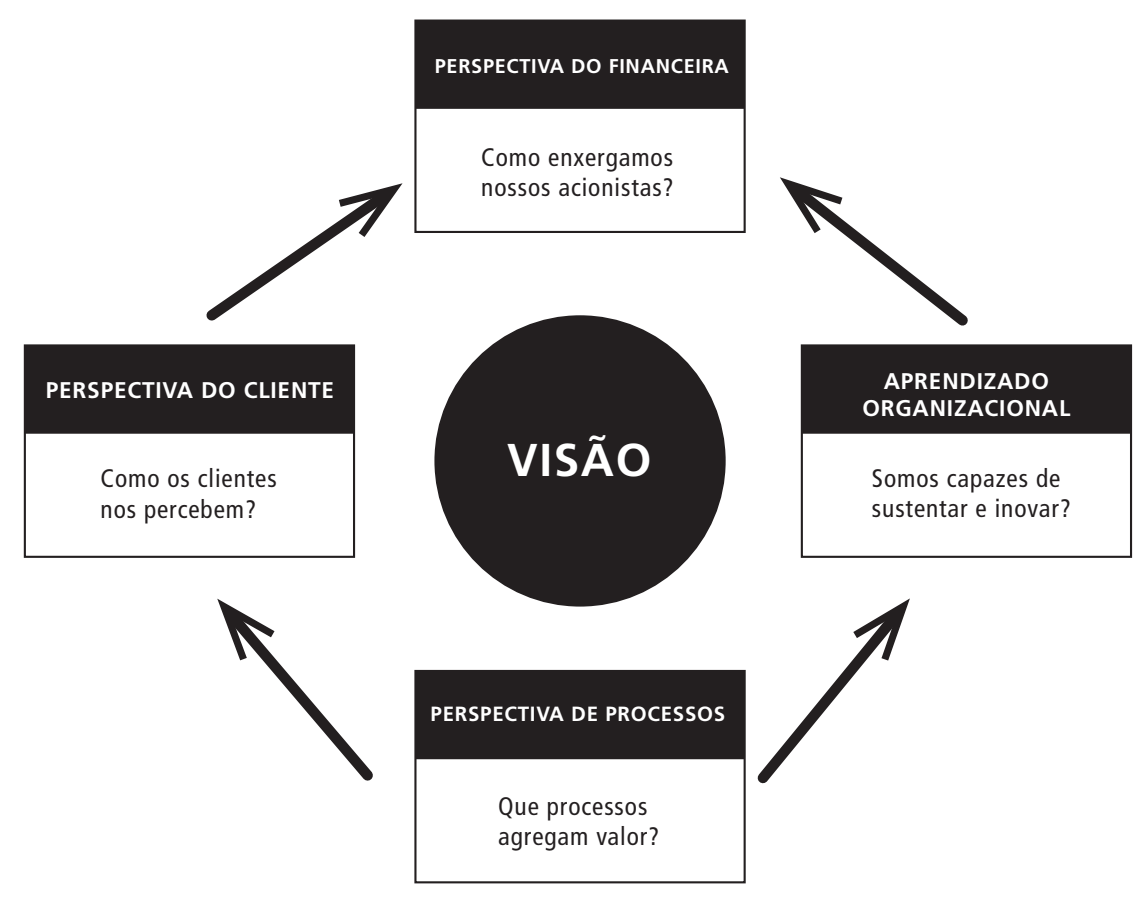

Fig.1: 0 Balanced Scorecard como Estrutura para Ação. Fonte: (Kaplan \& Norton, A estratégia em ação: Balanced Scorecard, 1997).

No livro "A estratégia em ação", Kaplan e Norton (1997) ilustram como várias empresas utilizam o Balanced Scorecard como um novo sistema de gestão da estratégia corporativa, fechando lacunas entre o desenvolvimento e a formulação da estratégia e a sua implantação, tais como:

- Visões e estratégias não executáveis - Em pesquisa realizada por empresa especializada, revelou-se que $59 \%$ da alta administração acreditam saber como implementar a visão, entretanto apenas $7 \%$ dos gerentes e linha de frente sabem como. Isso retrata que métodos tradicionais de implementação da estratégia geram lacunas para que a visão seja compartilhada em todos os níveis organizacionais.

- Estratégias não associadas às metas de departamentos e equipes - Refere-se ao fato de que programas de incentivos baseados em metas de produtividade estão relacionados a metas de curto prazo, dificultando a atenção do nível tático e operacional para implementação de estratégias.

- Estratégias não associadas à alocação de recursos - Constata-se falta de alinhamento dos programas e da alocação dos recursos às prioridades estratégicas de longo prazo, em vista de muitas empresas possuírem orçamentação anual. A consequência é que alocações de capital discricionárias raramente estão relacionadas às prioridades estratégicas.

- Existência de reporte tático, não estratégico Constata-se ausência de realimentação sobre como a estratégia está sendo implementada e como os seus resultados não permitem testar e aprender a estratégia na prática.

Magalhães e Brito (2007) citam também algumas críticas realizadas sobre modelos de reporte e de indicadores tradicionais, baseados apenas nos financeiros. Eles afirmam que a dicotomia entre o Planejamento Estratégico e o sistema de reporte periódico mina a credibilidade para o convencimento de clientes e funcionários, no que diz respeito à efetiva determinação da organização em implementar novas estratégias orientadas à satisfação do cliente e à inovação, entre outros.

No que se trata da dissociação entre objetivo e resultados, os objetivos necessitam de quantificação para explicitar a realidade gerencial a ser perseguida. Na ausência de análise quantitativa, torna-se difícil ressaltar as diferenças entre números e ações.

A metodologia Balanced Scorecard oferece duas vantagens: amplia as variáveis-chaves e promove a tradução dos objetivos estratégicos em objetivos concretos, mensuráveis e monitoráveis. 


\section{Alinhamento estratégico com BSC}

Dentre as dificuldades de gestão das organizações, o alinhamento do Planejamento Estratégico Empresarial está cada vez mais difícil, por falta de modelos e ferramentas adequadas.

Segundo os autores do BSC (Kaplan \& Norton, 1997), a implementação da estratégia começa pela capacitação e pelo envolvimento das pessoas que devem executá-la. As organizações que desejam a plena contribuição de todos envolvidos devem compartilhar suas visões e estratégias de longo prazo com os seus funcionários e incentivá-los a sugerir formas pelas quais a visão e a estratégia possam ser alcançadas.

Sugerem, inclusive, que o alinhamento de cima para baixo, enquanto estrutura hierárquica organizacional deva ocorrer para definição de uma visão compartilhada da estratégia, encorajando todos à participação. Um programa coerente e contínuo de educação da empresa, bem como um reforço sobre o desempenho obtido, constitui a base para a continuidade da estratégia.

Kaplan e Norton (2000) comentam ainda que os executivos usam o BSC como ferramenta nos processos de comunicar a estratégia e educar a organização. Em seguida, as empresas infundem, nos níveis mais baixos da organização, os scorecards de nível corporativo e os scorecards das unidades de negócio. A estratégia e o scorecard são comunicados de maneira holística, de forma que as pessoas e os departamentos nos níveis mais baixos desenvolvam seus próprios objetivos, à luz das prioridades mais amplas, e, finalmente, cada uma das organizações bem-sucedidas vincule a remuneração por incentivos ao BSC.

Em seus estudos sobre a aplicação do BSC em grandes organizações, os autores revelaram que aquelas bem-sucedidas tinham um padrão consistente na consecução do foco e do alinhamento estratégico. Embora cada organização abordasse o desafio à sua própria maneira, em ritmos e sequências diferentes, observou-se a atuação de cinco princípios comuns, conhecidos como princípios da organização focalizada na estratégia (Kaplan \& Norton, 2000).

Dentre os princípios comuns identificados, o primeiro procura traduzir a estratégia em termos operacionais. Os autores ressaltam a importância da participação e do envolvimento de todos os funcionários, pois eles criam um referencial geral para a descrição e implementação de estratégias, o mapa estratégico, que é uma arquitetura lógica e abrangente para a descrição da estratégia.

0 segundo princípio trata do alinhamento da organização à estratégia. Enfatiza a necessidade do alinhamento das unidades de negócio para criação de sinergia, integração das áreas funcionais à estratégia, e a prestação de serviços pelas unidades de apoio a custos menores e de melhor qualidade.
O terceiro princípio é transformar a estratégia em tarefa para todos. Traz a ideia de que todas as organizações focalizadas na estratégia exigem que todos os empregados compreendam a estratégia e conduzam suas tarefas cotidianas de modo a contribuir para o êxito da estratégia. As empresas implantaram, nos níveis mais baixos da organização, os scorecards do nível corporativo e os das unidades de negócio, sendo a estratégia e o scorecard comunicados de maneira holística, ou seja, para que as organizações atinjam seus objetivos, todos os seus membros devem estar alinhados com a estratégia. Para viabilizar esse alinhamento, propõe iniciativas, como a remuneração baseada no desempenho, a avaliação de desempenho pessoal baseada em outras perspectivas além da financeira, 0 treinamento de funcionários para que entendam a estratégia da empresa e a própria participação dos funcionários na elaboração da estratégia.

Kaplan e Norton (2000), no quarto princípio, comentam sobre converter a estratégia em processo contínuo. Nesse princípio, as empresas bem-sucedidas na adoção do BSC implementaram um processo de gerenciamento da estratégia.

No quinto princípio, Kaplan e Norton (2000) defendem que os líderes devem criar visões inspiradoras do lugar a que a empresa pretende chegar, compartilhando com todos os funcionários a clara visão de quem é o cliente-alvo. Além disso, devem direcionar a organização para a realização da estratégia, descentralizando poder e responsabilidade.

\section{TECNOLOGIA dA InFORMACÃO (TI) E BALANCED SCORECARD (BSC)}

A TI pode ser conceituada como recursos computacionais (har$d$ ware, software e serviços relacionados) que proveem serviços de comunicação, processamento e armazenamento de dados. Esses recursos são cada vez mais necessários para as empresas, pois elas estão se tornando cada vez mais dependentes de informações para alcançarem seus objetivos organizacionais e competirem no mercado, fazendo com que a área de TI exerça bem seu papel fundamental que é de dar suporte à estratégia empresarial (Rezende, 2002).

As organizações passaram a realizar planejamento e criar suas estratégias voltadas para o futuro, tendo como uma das principais bases a TI, em virtude de seus impactos sociais e empresariais (Rezende, 2002).

A acirrada competitividade tem feito com que as organizações vivam, constantemente, uma turbulência acentuada. É preciso que as empresas mantenham-se fortes objetivando obter resultados de curto prazo, mas com uma perspectiva de longo prazo.

0 autor (Rezende, 2002) ainda comenta que muitas empresas estão acreditando totalmente na TI para obtenção do 
sucesso, mas existem evidências de que muitas delas falham em aproveitar as potencialidades e benefícios estratégicos da tecnologia, por terem uma gestão pobre em TI.

Embora a gestão dessa área ainda seja relativamente pobre, os administradores têm procurado conhecer seu valor estratégico, considerando suas particularidades e as melhores práticas para seu gerenciamento. Esse conhecimento é essencial pelo investimento que representa e pela dependência cada vez mais significativa que as organizações têm de TI (Rezende, 2002).

A TI tem a responsabilidade de subsidiar os executivos com informações rápidas, assertivas e atualizadas, seja por meio de soluções personalizadas ou do uso de aplicativos do BSC (Rezende, 2002). Essa participação da TI às vezes se inicia nas fases preliminares do projeto (logo após a definição e descrição dos indicadores). Outras vezes, inicia-se com uma automação mais simplificada, com os próprios usuários gerando e administrando seus relatórios, ficando a TI num papel de staff. Nesse caso, a informatização do BSC será tarefa da TI para fases mais avançadas do projeto, quando já haverá maior maturidade no uso e medição dos dados necessários do projeto.

De acordo com Magalhães e Brito (2007), a implementação do BSC permite a otimização da utilização do ativo mais importante das empresas de hoje, que é a informação. Comparam a administração moderna com 0 ato de pilotar um avião. Nessa comparação, os autores citam que o BSC equivale ao painel de controle para gestores, sendo que nesse painel é organizada uma série de informações estratégicas num conjunto de indicadores que permitem: localizar problemas, definir rumos, prever turbulências, apontar tendências para o futuro e, principalmente, entender para onde vai à empresa.

Em gestão de TI, podem-se considerar modelos de governança. A Governança de TI engloba métodos para tornar mais transparentes, organizadas e legítimas as práticas de direção e monitoramento do desempenho das empresas, ou seja, engloba mecanismos implementados em diferentes níveis de uma empresa (Magalhães \& Brito, 2007).

\section{Análises e Resultados do Estudo de CASO}

Como forma de verificar a aplicabilidade do Balanced Scorecard como ferramenta de implantação do planejamento estratégico em uma área de Tecnologia da Informação, para fins deste estudo foi realizada análise em uma empresa do segmento de planos de saúde, mas que, por motivos de confidencialidade, o nome não é divulgado.

A empresa, cuja sede está situada em Brasília, possui unidades de atendimento em todas as capitais do Brasil e um quadro funcional de aproximadamente duas mil pessoas. Atua há
70 anos no mercado de saúde e presta atendimento a cerca de 600 mil vidas (clientes), conforme registros.

Para análise dessa empresa, contou-se com informações divulgadas em âmbito corporativo a respeito da metodologia utilizada para o planejamento estratégico e dos resultados apresentados desde sua implantação.

O planejamento estratégico corporativo foi definido em 2009, juntamente com o planejamento das Gerências Executivas. A abordagem utilizada teve por base 0 uso do Balanced Scorecard e contou com o conhecimento internalizado dos profissionais da empresa. 0 primeiro ciclo do planejamento estratégico finalizou-se em 2012 já apresentando bons resultados para a organização e para a área de tecnologia da informação. Para isso foram utilizadas algumas premissas, tais como:

- definição de direcionamento estratégico para a Tl;

- gerenciamento para melhorar o desempenho realizado em relação ao desejado;

- alinhamento da equipe de TI com a estratégia Corporativa;

- definição de um padrão de gerenciamento para os gestores de Tl;

- criação de um referencial para apoiar a comunicação da TI com as demais gerências de negócio;

- criação de um ambiente de trabalho orientado para a estratégia de TI e organizacional.

Inicialmente foram realizados workshops para divulgação e alinhamento das técnicas do Balanced Scorecard. Foram envolvidos os executivos do alto escalão, os gerentes de áreas de negócio, coordenadores e os analistas sêniores.

Em workshops específicos e com público estratégico e tático, o mapa estratégico com os objetivos e metas a médio e longo prazo foram definidos. Os gerentes de negócio, coordenadores e analistas sêniores participaram da construção das proposições de ações e iniciativas.

Em avaliação e apreciação conjunta, todos os envolvidos puderam priorizar e aprovar as iniciativas, ações estruturantes e operacionais. Embora isso tenha ocorrido no primeiro ano (2009), foram realizadas revisões semestrais e anuais do planejamento, vislumbrando identificar melhorias e correções imediatas.

Em 2012 foi divulgado o relatório de análise situacional, contendo resultados de estudos elaborados por empresas e consultorias especializadas, materiais divulgados por Agência Regulatória e análise interna. 
Foram observadas ameaças como a possível redução do poder de aquisição da população em função do aumento da taxa de inflação, podendo gerar impactos de manutenção dos contratos firmados de planos de saúde. Outra ameaça identificada foi o crescente investimento de Agências Regulatórias em novas exigências que demandam adaptações por parte das operadoras de saúde.

Em se tratando das oportunidades, a inibição do alto índice de desemprego possibilita as classes C e D procurar os serviços do setor de assistência médica.

Como ponto forte, a avaliação demonstrou que a definição de metas que possuem investimentos constantes na saúde preventiva tem surtido efeitos na contenção dos gastos com despesas assistenciais. Porém, tem como ponto fraco o desequilíbrio entre preço e qualidade oferecida pela operadora, que deixa a desejar na prestação de serviços.

Vale destacar que esta avaliação refere-se ao primeiro ciclo do planejamento estratégico da organização e que a análise possibilitou averiguar quais são os investimentos primordiais a serem mantidos na continuidade da estratégia.

Como resultado desse processo, concluiu-se que a verticalização terá continuidade intensa no $2^{\circ}$ ciclo do planejamento estratégico (2013/2016) com maior incidência de investimentos na rede própria. Essa medida visa não apenas à redução da sinistralidade na rede particular, tendo em vista evitaremse maiores custos à organização, como também ao atendimento com qualidade das exigências regulatórias aos usuários.

Os investimentos tecnológicos também contribuíram para trazer maior eficiência operacional à organização e para reduzir os seus custos. Exemplo disso é o investimento em prontuários médicos eletrônicos e sistema de autorizações de procedimentos, que já demonstram agilidade no atendimento e maior confiabilidade nos procedimentos operacionais, conforme avaliação realizada pela empresa.

A Gerência de Tecnologia da Informação tem o seu próprio planejamento estratégico, todavia integrado aos objetivos e às metas da empresa. Mensalmente os gerentes de negócio, juntamente com o gerente de $\mathrm{TI}$, participam de reuniões de priorização e de revisão do atendimento da Gerência de TI.

Para a organização, o uso do BSC aplicado à implementação das diretrizes pela Governança Corporativa contribuiu com a definição de resultados mensuráveis e identificados da $\mathrm{TI}$, quanto ao valor gerado para o alcance dos objetivos estratégicos.

A estratégia de investimento e de custeio para novas tecnologias e manutenções necessárias é definida a cada revisão anual, alinhada às necessidades das áreas intervenientes, gerando uma relação de causa e efeito.

No último ano de 2012, no relatório anual foi apresentado um aumento de $18 \%$ no uso dos serviços disponibilizados no sítio da empresa, desonerando outros tipos de canais de atendimento mais caros para a empresa.

Foram incluídos no referencial estratégico do planejamento da TI, conforme cada perspectiva estratégica:

\section{- CLIENTES}

Educar e treinar usuários.

Desenvolver processos eficientes e transparentes. Buscar satisfação dos usuários de TI.

\section{- PROCESSOS INTERNOS}

\author{
Planejamento e Organização \\ Implantar PETI. \\ Gerenciar investimento de TI. \\ Avaliar e gerenciar os riscos de TI. \\ Gerenciar Projetos.

\section{ENTREGA E SUPORTE} \\ Garantir continuidade dos serviços de TI. \\ Gerenciar central de serviços e incidentes. \\ Gerenciar problemas. \\ Garantir segurança de sistemas. \\ Garantir operações.

\section{AQUISIÇÃO E IMPLEMENTAÇã̃O \\ Garantir disponibilidade de infraestrutura de TI - Clientes.}

\section{- APRENDIZADO E CRESCIMENTO}

Capacitar colaboradores da GTI. Prover reorganização estrutural. Investir na terceirização.

\section{- ORÇAMENTO}

Assegurar recursos financeiros.

Aprimorar a política de economicidade.

Durante a etapa de alinhamento com a estratégia da organização, todas as diretrizes foram revisitadas a fim de identificarem-se necessidades específicas de TI (informação, infraestrutura, hardware, software ou serviços).

Das necessidades identificadas, algumas ações foram priorizadas e executadas pela TI, e, por conseguinte, os seguintes resultados foram alcançados, conforme exemplos da tabela abaixo: 
Tabela 2: Necessidades e Resultados Alcançados

\begin{tabular}{|c|c|c|}
\hline Necessidades & Objetivo de Resposta & Resultados Alcançados \\
\hline $\begin{array}{l}\text { Aquisição de software para } \\
\text { monitoramento de recursos de TI. }\end{array}$ & $\begin{array}{l}\text { Criar e manter inventário do parque tecnoló- } \\
\text { gico de TI e monitoramento em tempo real, } \\
\text { com vistas à TI produzir ações preventivas. }\end{array}$ & $\begin{array}{l}\text { Melhor dimensionamento das necessidades } \\
\text { e aquisições a serem realizadas. } \\
\text { Estabelecimento de Acordos de Nível de } \\
\text { Serviços, ampliando a disponibilidade, com } \\
\text { menor tempo de resposta a incidentes, e } \\
\text { diminuição do tempo de parada total, que } \\
\text { antes chegava até } 24 \text { horas de interrupção } \\
\text { de serviços em média, e após com redu- } \\
\text { ção em } 70 \% \text {. }\end{array}$ \\
\hline $\begin{array}{l}\text { Atualização do parque } \\
\text { tecnológico }\end{array}$ & $\begin{array}{l}\text { Atualizar o parque tecnológico a partir do } \\
\text { estabelecimento de uma política de atuali- } \\
\text { zações de equipamentos contínua contem- } \\
\text { plando necessidades específicas. }\end{array}$ & $\begin{array}{l}\text { Adequação dos equipamentos disponíveis } \\
\text { às atividades executadas em } 100 \% \text {. }\end{array}$ \\
\hline $\begin{array}{l}\text { Aquisição de licença de uso de } \\
\text { software proprietários. }\end{array}$ & $\begin{array}{l}\text { Atender às necessidades específicas de áreas } \\
\text { de negócio. }\end{array}$ & $\begin{array}{l}\text { Atendimento às necessidades administrati- } \\
\text { vas e operacionais. } \\
50 \% \text { do plano realizado, e em andamento. }\end{array}$ \\
\hline $\begin{array}{l}\text { Aquisição de licença de uso de } \\
\text { softwares de apoio ao gerencia- } \\
\text { mento de projetos e gerencia- } \\
\text { mento de portfólio. }\end{array}$ & $\begin{array}{l}\text { Criar um sistema de apoio à gerência de pro- } \\
\text { jetos com um conjunto de funcionalidades e } \\
\text { características que os tornem indicados para } \\
\text { implementação em ambientes corporativos. }\end{array}$ & $\begin{array}{l}\text { Possibilidade de acompanhamento, antes } \\
\text { não realizado, das etapas dos projetos, } \\
\text { execução das tarefas, monitoramento dos } \\
\text { envolvidos e controle orçamentário/finan- } \\
\text { ceiro, por meio do gerenciador de projetos. }\end{array}$ \\
\hline $\begin{array}{l}\text { Aquisição de licença de uso de } \\
\text { software básico para estações } \\
\text { de trabalho }\end{array}$ & $\begin{array}{l}\text { Fazer a adequação das configurações locais } \\
\text { quanto ao sistema operacional e aplicativo } \\
\text { de escritório. }\end{array}$ & $\begin{array}{l}\text { Regularização e customização do ambiente } \\
\text { do usuário. }\end{array}$ \\
\hline $\begin{array}{l}\text { Atualização da infraestrutura de } \\
\text { rede }\end{array}$ & $\begin{array}{l}\text { Prover serviços de alta disponibilidade (rede } \\
\text { wi-fi, switch core e firewall. }\end{array}$ & $\begin{array}{l}\text { Ampliação da disponibilidade em aten- } \\
\text { der à demanda de crescimento do uso de } \\
\text { tecnologias. }\end{array}$ \\
\hline Implantação de Processos ITIL & $\begin{array}{l}\text { Desenvolver métodos normatizados para } \\
\text { padronização das ações e abranger quali- } \\
\text { dade ao serviço prestado. }\end{array}$ & $\begin{array}{l}\text { Medição e controle mensais dos índices de } \\
\text { atendimento (primeira medida apresentada } \\
\text { em 2013, com comparação dos dados de } \\
\text { 2012). } \\
\text { Certificação ISO IEC } 20000 \text { - Gerenciamento } \\
\text { de Serviços de TI. }\end{array}$ \\
\hline Reestruturação das equipes & $\begin{array}{l}\text { Definir as equipes focais para o atendimento } \\
\text { do negócio. }\end{array}$ & $\begin{array}{l}\text { Especialização das equipes por possuírem } \\
\text { foco em seu processo de desenvolvimento. }\end{array}$ \\
\hline
\end{tabular}


Foi verificado, por meio da perspectiva de processos internos, que existem pontos críticos a serem melhorados com vistas a otimizar os investimentos tecnológicos. Duas perspectivas foram definidas: atuar com tempestividade na identificação e implantação de novas soluções; e possuir sistemas de informações integrados que suportem os processos internos e tomadas de decisões.

Observou-se que para haver tempestividade na implantação de soluções, a TI necessitava conhecer os processos da organização, e mais do que isso, gerir informações estratégicas para subsidiar a camada decisória em suas ações. Porém, o que foi possível analisar é que a TI ainda possuía um modelo de atendimento reativo, que sustentava sua atuação no mero atendimento pontual de demandas registradas por usuários, sem nenhum conhecimento estratégico ou negocial que possibilitasse uma visão holística para definição de sistemas sustentáveis.

Embora seja imperativo o conhecimento dos processos e sua gestão estratégica conjunta, não seria possível aguardar que toda uma organização fosse reestruturada para que a área de TI pudesse atuar de forma efetiva em suas visões.

Com isso foram aprovadas iniciativas para a revisão e modelagem de processos organizacionais para as Gerências Executivas, com objetivo de definição de modelos sistêmicos de negócio sustentáveis e de longo prazo.

Entretanto a médio e curto prazo foram definidas ações estruturantes para as bases de dados dos diversos sistemas, de forma a unificá-las, transformando-as em uma base de dados única, ou seja, corporativa e gerenciável.

Também foram concebidos modelos de atendimento de negócio, com a especialização de setores para avaliação de impacto nas definições de soluções tecnológicas corporativas integradas.

Com a certificação ISO IEC 20000, os processos foram normatizados oferecendo maior qualidade na gestão, acompanhamento e operacionalização dos planos. Isso melhorou não só a visão do cliente interno e externo, mas padronizou o modelo de trabalho e permitiu o compartilhamento de um bom programa de comunicação e de atendimento.

Os indicadores de TI e da Organização são administrados por soluções tecnológicas como Cognos Business Intelligence e Oracle BAM. Esses sistemas foram customizados para retratar informações adequadas para o acompanhamento do novo modelo de trabalho, a exemplo do acompanhamento das perdas operacionais ocorridas em relação à ausência de operacionalização sistêmica.

Além dos mencionados sistemas, a implantação de solução de Servisse Desk possibilitou o acompanhamento de outros indicadores, como o de mensuração da disponibilidade dos serviços de $\mathrm{TI}$, cuja meta de $90 \%$ ainda não foi atingida.

Para o acompanhamento e gestão das estratégias, a Governança de TI definiu três etapas:

- Equipe da Governança de TI: compara desempenho com a meta do mês (Como estamos?). Analisa os desvios (Por quê?). Revisa os status das iniciativas relacionados aos indicadores (0 que está sendo feito?). Atualiza e define, caso necessário, novas ações (0 que iremos fazer?). Projeta qual o desempenho para os próximos períodos com base no atual (Como estaremos?).

- Reuniões Mensais: analisam-se os resultados apresentados pela Governança de TI (revisões do BSC) e definem-se ações com foco nos resultados mais críticos, sempre apoiados pelo BSC.

- Comunicação: os resultados e ações são divulgados por meio de registro da reunião, com as definições de cada coordenação, metas e prazos.

A tabela abaixo demonstra os resultados dos indicadores de TI, comparados entre os períodos de 2011 e 2012.

Tabela 3: Resultados Indicadores do Atendimento dos Serviços de TI

\begin{tabular}{|l|l|l|}
\hline \multicolumn{1}{|c|}{ Serviços } & \multicolumn{1}{|c|}{ SLAs violados em 2011 } & \multicolumn{1}{c|}{ SLAs violados em 2011 } \\
\hline $\begin{array}{l}\text { Gerenciamento de Incidentes e } \\
\text { Requisições }\end{array}$ & $68 \%$ das requisições & $47 \%$ das requisições \\
\hline Gerenciamento de Problemas & $\begin{array}{l}92 \% \text { das requisições tiveram SLA } \\
\text { violado. }\end{array}$ & $40 \%$ das requisições tiveram SLA violado \\
\hline $\begin{array}{l}\text { Gerenciamento de Segurança da } \\
\text { Informação }\end{array}$ & $\begin{array}{l}37 \% \text { das requisições tiveram SLA } \\
\text { violado. }\end{array}$ & $17 \%$ das requisições tiveram SLA violado. \\
\hline Gerenciamento da Capacidade & $\begin{array}{l}50 \% \text { das requisições tiveram SLA } \\
\text { violado. }\end{array}$ & $10 \%$ das requisições tiveram SLA violado. \\
\hline Gerenciamento de Disponibilidade & $\begin{array}{l}2 \% \text { das requisições tiveram SLA } \\
\text { violado. }\end{array}$ & $1 \%$ das requisições tiveram SLA violado. \\
\hline
\end{tabular}


As renegociações de SLA ainda são constantes, porém a redução é visível conforme dados apresentados. Os demais processos de gerenciamento não tiveram sua apuração realizada, pois os indicadores foram desenvolvidos nas ferramentas de gerenciamento no final de 2012.

No que tange ao Gerenciamento de Serviços de TI, no primeiro trimestre de 2012 foi realizada pesquisa de satisfação com os usuários requisitantes de $\mathrm{TI}$, e os resultados demonstram que nesse ano, $61 \%$ das 373 pessoas que responderam a pesquisa consideraram-se totalmente satisfeitas com as ações adotadas pela $\mathrm{TI}$, e $61 \%$ concordaram totalmente que a qualidade do atendimento superou suas expectativas.

Em comparação aos resultados do ano seguinte (2013), a pesquisa relatou um aumento de $10 \%$ na melhora da satisfação com o atendimento de TI. Embora a meta anual seja de $90 \%$ de satisfação dos usuários, já é possível observar que o acompanhamento por meio de indicadores mensuráveis e a possibilidade de revisão das ações, metas, iniciativas e objetivos, oportunizam as correções necessárias para bom andamento da organização.

Em suma, a aplicação do BSC na Organização e pela Governança de Tl é muito mais do que apenas acompanhar os indicadores. A gestão tornou-se mais objetiva e os colaboradores sentem-se mais envolvidos em suas atividades, conforme pesquisa realizada em âmbito organizacional para a revista. A cultura e o compromisso das pessoas estão voltados para a melhoria do desempenho. Passou a existir uma maior coesão e alinhamento da equipe, com a certeza de que a TI está alinhada com o negócio.

Viu-se que a área de TI ganhou maior visibilidade com relação aos esforços empreendidos para atender às demandas, tendo uma maior confiabilidade por parte das outras áreas da empresa. A TI também está sendo acionada pelas outras Gerências quando da revisão de suas estratégias.

Verificou-se que havia uma preocupação por parte de gestores com relação a uma gestão específica, porém, no caso da área de $\mathrm{TI}$, houve maior interação entre as áreas. Atualmente 0 BSC está sendo revisto e testado na empresa com vistas à proposição de ações e correções para 2014, e algumas outras áreas de negócio estão utilizando o BSC para auxiliar o seu plano.

A definição de um planejamento estratégico por si só não agregaria valor à organização, pois o principal ganho observado com a implantação da estratégia adveio do acompanhamento das ações e dos seus resultados, por meio de indicadores previamente definidos e dentro de uma escala de priorização de análise de impacto conforme perspectiva definida pelo Balanced Scorecard.

\section{CONCLUSÕES}

O BSC apresenta-se como um instrumento importante para a definição da estratégia e para a sua gestão. 0 que se vê em muitas organizações é que ainda estão se utilizando de diversas iniciativas para melhorar sua operação, porém são dissociadas da estratégia e exigem grandes mudanças.

0 estudo confirma que o BSC aplicado como um sistema gerencial fornece a estrutura adequada para a tradução da estratégia, assim como Kaplan e Norton já identificaram em seus estudos.

Talvez o que as empresas ainda falhem na definição da sua estratégia, é por se apegarem apenas aos indicadores financeiros e econômicos.

Todos os demais são tão importantes quanto este, sendo necessário monitorar também as perspectivas relacionadas ao mercado, aos processos internos e às pessoas.

Conforme observado no estudo, pode-se considerar que a aplicação do BSC possibilitou uma gestão mais efetiva e com resultados satisfatórios já no primeiro ciclo. As técnicas utilizadas no BSC trazem uma visão mais clara para avaliação do desempenho dos indicadores e permite maior visibilidade para a área de TI, por indicar quais são os resultados e aonde se quer chegar.

Com o envolvimento e o compromisso dos colaboradores de TI no processo, percebe-se a busca em desenvolver suas atividades dentro de um contexto normatizado, o que os torna mais confiantes na elaboração e consecução das metas. Percebeu-se também que os gestores de negócio passaram a valorizar mais a área de $\mathrm{Tl}$, buscando mais a participação da área em suas definições estratégicas.

É importante que as demais áreas de negócio estabeleçam seu planejamento estratégico, mesmo que a organização já possua o seu. É preciso que os gestores estejam envolvidos e cientes da importância do seu setor para o processo e para os resultados alcançados.

A área de TI apresenta resultados claros, porém precisa de adequações com relação ao desenvolvimento de ações de curto prazo. A área de TI também precisa analisar os investimentos de longo prazo, pois são muitos os fatores externos que influenciam a sua direção. São muitas as tecnologias disponíveis, e uma escolha pode ser um gasto maior no futuro em função de uma estratégia errada.

Isso explica, talvez, por que os demais processos de gerenciamento de serviços de TI não estão com suas medidas bem definidas. Houve uma disposição expressiva em analisar esses processos com a cautela de direcionar ações e investimentos.

A empresa confia no modelo, e com a aplicação na TI podese considerar que o BSC é flexível e pode contribuir como ferramenta de gestão estratégica para várias áreas da empresa. 
A bibliografia existente é expressiva e oferece condições de qualquer organização utilizar de seus conceitos, abordagens, técnicas e lições aprendidas para a elaboração do seu planejamento estratégico e ainda com o uso do Balanced Scorecard.

Admite-se que o BSC é um modelo de gestão que traduz a estratégia da organização em objetivos práticos, criando uma visão compartilhada, e que procura garantir a sustentabilidade nas perspectivas financeiras de clientes, de processos internos, de aprendizado e de crescimento.

Conclui-se que o Balanced Scorecard, como uma ferramenta de gestão estratégica, produz um claro entendimento de como ações isoladas podem impactar não apenas a sua área, mas também toda a estratégia da empresa. Dessa forma, o BSC é a ferramenta que auxilia a relação das ações de hoje com as metas de longo prazo, promovendo a sinergia necessária à empresa para garantir o sucesso em seus objetivos.

\section{REFERÊNCIAS}

BATEMAN, T. S. (2007). Administração: liderança e colaboração no mundo competitivo. São Paulo: McGraw-Hill.

BETHLEM, A. (1998). Estratégia empresarial: conceitos, processos e administração estratégica. São Paulo: Atlas.

CHIAVENATO, I., \& Sapiro, A. (2003). Planejamento estratégico. Rio de Janeiro: Elsevier.

GIL, A. C. (2002). Como elaborar projetos de pesquisa. São Paulo: Atlas.

GRAEML, A. R. (2003). Sistemas de informação: 0 alinhamento da estratégia de $\mathrm{TI}$ com a estratégia corporativa. $2^{\circ}$ ed. São Paulo: Atlas.

KAPLAN, R. S., \& Norton, D. P. (1997). A estratégia em ação: Balanced Scorecard. (L. E. Filho, Trad.). Rio de Janeiro: Elsevier.

KAPLAN, R. S., \& Norton, D. P. (2000). Organização orientada para a estratégia: como as empresas que adotam 0 Balanced Scorecard prosperam no novo ambiente de negócios. Rio de Janeiro: Elsevier.

MAGALHÃES, I. L., \& Brito, W. (2007). Gerenciamento de serviços de TI na prática: uma abordagem com base na ITIL: inclui ISO/IEC 20.000 e IT Flex. São Paulo: Novatec Editora.
MINTZBERG, H., AHLSTRAND, B., \& LAMPEL, J. (2000). Safári de estratégia: um roteiro pela selva do planejamento estratégico. (N. MONTINGELLI JR, Trad.) Porto Alegre: Bookman.

REZENDE, D. A. (2002). Tecnologia da Informação integrada à inteligência empresarial: alinhamento estratégico e análise da prática nas organizações. São Paulo: Atlas. 